\title{
A Bony Projection- Case Report
}

\author{
Reshma Suvarna* \\ Department of Oral Medicine \& Radiology, AJ Institute of Dental Sciences, India
}

Received: January 27, 2018; Published: February 02, 2018

*Corresponding author: Reshma Suvarna, Department of Oral Medicine \& Radiology, AJ Institute of Dental Sciences, India, Tel: +919449966216; Email: itsreshma_11@yahoo.co.in

\begin{abstract}
Eagle's syndrome (ES) is noticed when there is an elongated styloid process or calcified stylohyoid ligament which causes recurrent throat pain or foreign body sensation, dysphagia, or facial pain. It is not usually reported but it is more prevalent than generally considered. In adults the length of the styloid process is approximately $25 \mathrm{~mm}$ with a tip located between the external and internal carotid arteries, lateral to the pharyngeal wall and the tonsillar fossa. Ossification of the stylohyoid and stylomandibular ligament leads to prolongation of the styloid process causing clinical symptoms. It is diagnosed radiologically as well as by physical examination. Advanced radiological modality like CBCT is very valuable in knowing the exact length and extent of the styloid process. The treatment is primarily surgical. The physician's knowledge of possible clinical variations and its diverse symptomatology is critical.
\end{abstract}

Keywords: Eagle's syndrome; Stylohyoid syndrome; Elongation; Styloid process

\section{Introduction}

Watt W Eagle [1] was the first to describe the clinical findings of eagle's syndrome in the year 1937. Eagles syndrome or stylohyoid syndrome, is the symptomatic elongation of the styloid process or mineralization of the stylohyoid ligament complex. The styloid process is a bony projection, which is situated immediately anterior to the stylomastoid foramen. It is of cylindrical form which projects downwards from the inferior surface of the temporal bone towards the front, downwards and medially narrowing at the tip. The position of the tip is important, as it is situated between the internal and external carotid arteries, laterally from the pharyngeal wall and just behind the tonsil fossa. Two ligaments and three muscles are attached to the styloid process.

Stylopharyngeus attaches medially and from the posterior side close to the base of the process, stylohyoid from the posterior side and laterally on the central part of the process and styloglossus starting from the anterior part of the process is seen next to the tip. The muscles are supplied by glossopharyngeal, facial and hypoglossal nerve. The stylohyoid ligament extends from the tip of the styloid process up to the lesser cornu of the hyoid bone and the stylomandibular ligament, commences under the attachment of styloglossus muscle and ends near the angle of mandible [2]. ES is an uncommon entity which is not always suspected in daily practice.

Only about $4 \%$ of the population is believed to have an elongated styloid process. Patients with ES presents with a sore throat, ear pain, or even with symptoms of foreign Body in the pharynx secondary to pharyngeal and cervical nerve interactions. Symptoms are common in females. Patients are usually above 30 years. As the symptoms are variable and nonspecific, patients seek treatment in several different clinics [3]. We, here report a case of eagle's syndrome who presented with neck pain.

\section{Case History}

A 44 year old male patient reported to our OPD, with a chief complaint of pain in left side of the ear and neck since 1 year (Figure 1). History revealed that the pain was unilateral, insidious in origin, dull to moderate in intensity and intermittent in nature. The pain was characterized by needle-like, piercing pain inside the left ear, pain was associated with headache. The intensity of pain was aggravated by movements such as looking up and turning face to right side and became worse during deglutition. In addition, patient also had a sensation of foreign body in throat while swallowing. There was no relevant medical or dental history.

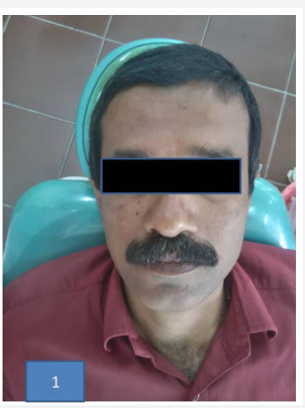

Figure 1: Patient, suffering from neck pain. 


\section{Open Access Journal of Surgery}

Patient was moderately built and nourished, and mentally sounds on extra oral examination, temporomandibular joint showed bilaterally symmetrical movements, clicking was present on left side, along with tenderness in the pre-auricular region. Also tenderness between upper end of sternocleidomastoid muscle and angle of mandible. A small bony pointed projection was palpable in the right submandibular region at the anterior border of sternocleidomastoid muscle, which was tender. Mouth opening was $32 \mathrm{~mm}$ and mandibular protrusion was $10 \mathrm{~mm}$. On intraoral examination, he had a normal complement of teeth, with no carious or filled teeth, and with moderate stains and calculus. The medial pterygoid muscle was tender on palpation on left side.

Based on the history and clinical findings, a provisional diagnosis of Myofacial Pain Dysfunction Syndrome was put forth. And Eagles syndrome was considered under differential diagnosis. Panoramic radiograph showed that the length of left styloid process to be $48 \mathrm{~mm}$, with Langlais type I pattern (Figure 2). Considering the elongated styloid process and suspecting eagle's syndrome, CBCT was advised. CBCT scan showed unilateral elongation of the styloid process towards the left. The actual length of the styloid process was processed using CBCT in various sections (Figure 3A-3D), and was found to be $62.2 \mathrm{~mm}$ in comparison with the $\mathrm{OPG}$, which was $48 \mathrm{~mm}$. Almost a difference of $14 \mathrm{~mm}$ was noticed between the two modalities. Hence showing, CBCT as the most reliable radiologic modality, to be carried out in cases where styloid process elongation is suspected. Based on the history, clinical findings and investigations, a final diagnosis of Eagles Syndrome was given and the patient was referred, for the removal of the styloid process.

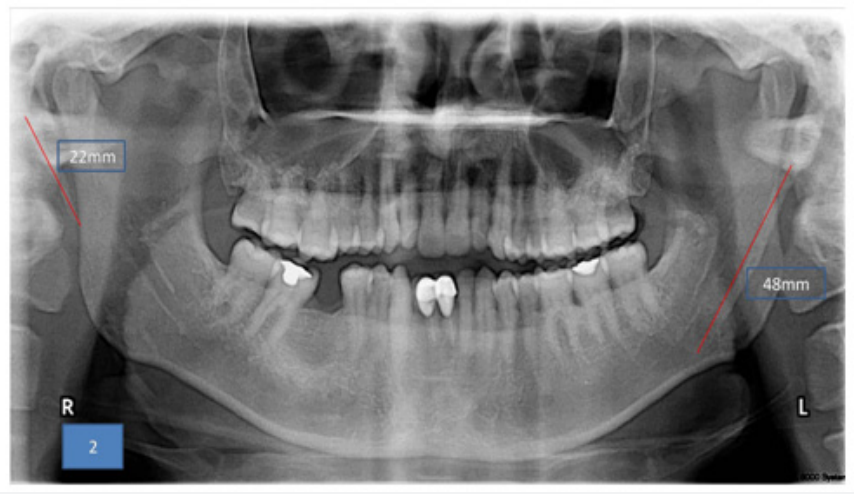

Figure 2: OPG of the patient revealing elongated left styloid process, with measurement.
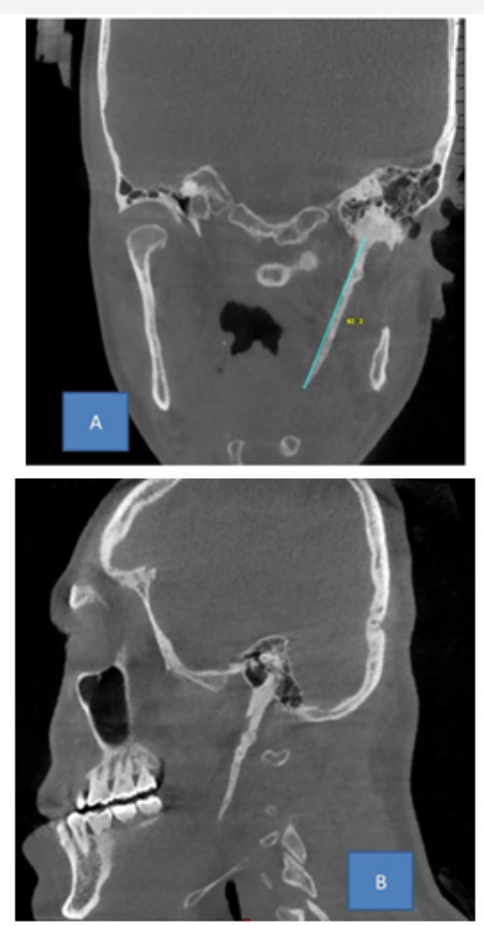

Figure 3: $\mathrm{CBCT}$ revealing elongation of left styloid process, in various sections. A \& B Coronal and sagittal section showing elongation of left styloid process.

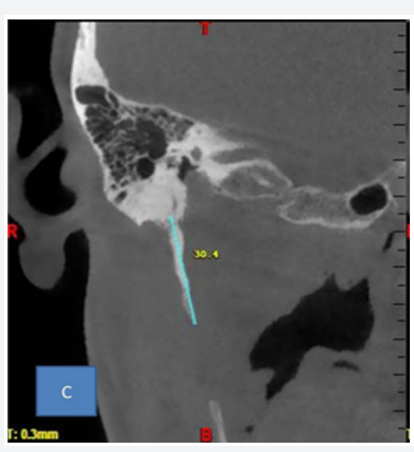

Figure 3C: Coronal section showing right styloid process, whose length is under normal limits.

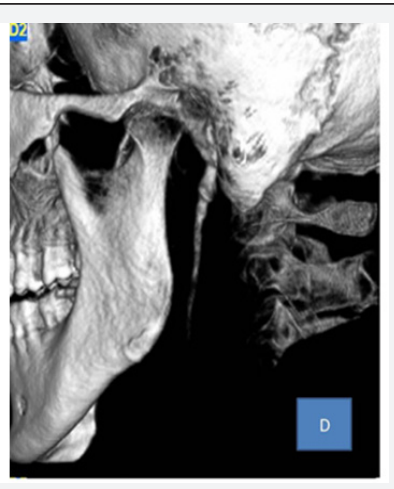

Figure 3D: view of the elongated left styloid process. 


\section{Discussion}

Stylos refers to pillar derived from a Greek word. Styloid process, stylohyoid ligament and small horn of the hyoid bone developmentally originate from the second bronchial or hyoid arch. The elongation of styloid process can be congenital or calcification of stylohyoid/stylomandibular ligament as a result of ageing and other degenerative process. Because of its cartilaginous origin, the ligament has the potential to mineralize. There exists difference between true Styloid Process elongation and secondary ossification of the stylohyoid ligament. True elongation results in a smooth, regular, well corticated bone of different lengths projecting continuously from the skull base as seen in our case. Secondary stylohyoid ligament ossification results in an irregular surface with thickened areas that extend towards the lesser horn of the hyoid bone, usually with prominent medial angulations.

The ossified complex may or may not be segmented with a thin cortex or a bulky irregular contour [4]. Other names include "Elongated Styloid Process Syndrome", "Carotid Artery Syndrome", "Styloid Process Neuralgia", "Stilalgia", "Stylohyoid Syndrome" and "Pseudohyoid Syndrome" [5]. Eagle's syndrome must always be considered for the differential diagnosis of pains localized in the head-neck area, especially in persons above the age of 30 years. It is an uncommon but one of the main cause for chronic head and neck pain. The characteristic dull and nagging pain which becomes bad during deglutition and can be felt during palpation of the tonsillar fossa is the hallmark sign [3]. Elongated styloid process may lead to compression of many vital structures and cause inflammatory changes like chronic pain in the pharyngeal region, radiating otalgia, phantom foreign body sensation (globus hystericus), pain in the pharyngeal region, dysphagia etc,. And also can cause craniofacial as well as cervical pain, difficulties while swallowing, secondary gloss pharyngeal neuralgia, radiating pain into orbit and maxillary region [6].

Various pathophysiological mechanisms for the pain of ES include [7]:

a) Compression of the neural elements, the glossopharyngeal nerve, the chorda tympani by the elongated styloid process and the lower branch of the trigeminal nerve;

b) Fracture of the ossified stylohyoid ligament, is usually followed by proliferation of granulation tissue causing pressure on surrounding structures and results in pain;

c) Impingement on the carotid vessels by the styloid process, causing irritation of the sympathetic nerves in the arterial sheath;

d) Degenerative and inflammatory changes in the tendonous portion of the stylohyoid insertion;

e) Irritation of the pharyngeal mucosa by direct compression of the styloid process; f) Stretching and fibrosis of the fifth, seventh, ninth, and tenth cranial nerves in the post-tonsillectomy period.

Langlais et al. [8] in the year 1986 put forth a radiological classification for elongated styloid process:

a) Type I (Elongated styloid process) pattern that represents an uninterrupted, elongated styloid process, which is reported in our case.

b) Type II (Pseudo articulated styloid process) is characterized by the styloid process being joined to the stylohyoid ligament by a single pseudo articulation which gives the appearance of an articulated elongated styloid process.

c) Type III (Segmented styloid process) consists of interrupted segments of the mineralized ligament, which gives the appearance of multiple pseudo articulations within the ligament.

Differential diagnosis for eagles syndrome includes laryngopharyngeal dysesthesia, temporomandibular arthritis, glossopharyngeal and trigeminal neuralgia, chronic tonsillopharyngitis, Sluders syndrome, cluster type headache, temporal arteritis, cervical vertebral arthritis, benign or malignant neoplasm, migraine, tension headache, atypical facial pain, myofascial pain syndrome, tonsillitis, psychosomatic disease, trigeminal neuralgia, TMJ disorders, temporal arteritis, unerupted or impacted molar teeth and faulty dental prostheses, costens syndrome and trotters syndrome [9].

The most reliable radiological investigation in recent times is the CBCT, where the exact length and extent of the styloid process can be studied. This syndrome may be treated conservatively or surgically. Conservative treatment includes transpharyngeal injection of steroids with lignocaine, nonsteroidal antiinflammatory drugs, diazepam, application of heat, traditional chinese medicines, and transpharyngeal manipulation by manually fracturing the styloid process. The most satisfactory, effective and followed treatment is surgical shortening of the styloid process, either through an intraoral or external approach. Advantage of an external approach is the proper exposure of the styloid process and the adjacent structures, and this advantage outweighs all the other considerations and also facilitates the resection of a partially ossified stylohyoid ligament. Transoral resection prevents outside scars, but carries the risk of deep cervical infection with possible injury to the neurovascular bundles [10].

\section{Conclusion}

The elongated styloid process syndrome can be easily diagnosed by a detailed history, physical examination, and radiological investigations. It should always be taken to consideration in patients with a sore throat and pain while swallowing, feeling of foreign body in the throat and facial pain. Clinicians should consider the possibility of Eagle's syndrome 
when both the clinical and radiographic evidence are positive. Every practitioner should be aware of it to prevent misdiagnosis and unnecessary trouble to the patient.

\section{References}

1. Sadaksharam J, Singh K (2012) Stylocarotid syndrome: An unusual case report. Con Temp Clin Dent 3(4): 503-506.

2. Teki S, Ashalatha D, Babu S, Kumari KL, Prasad S, Vasanthi A (2014) Eagle's Syndrome-Elongated Styloid Process. IOSR-JDMS 13(5): 31-33.

3. Khandelwal S, Hada YS, Harsh A (2011) Eagle's syndrome-A case report and review of the literature. Saudi Dent J 23(4): 211-215.

4. Pushpalatha K, Bhat D (2014) Bilaterally Elongated Styloid Process-A Case Report. International Journal of Scientific Study 2(4): 100-102.

5. (2013) The Internet Journal of Biological Anthropology.
6. Kosar MI, Atalar MH, Sabancioğullari V, Tetiker H, Erdil FH, Et al. (2011) Evaluation of the length and angulation of the styloid process in the patient with pre-diagnosis of Eagle syndrome. Folia Morphol (Warsz) 70(4): 295-299.

7. Ceylan a, Köybaşioğlu a, Celenk F, Yilmaz O, Uslu S (2008) Surgical treatment of elongated styloid process: experience of 61 cases. Skull Base 18(5): 289-295.

8. Chauhan S, Mohan V, Chauhan R (2016) Bilateral Elongated Styloid process-A Case Report. J Dent Specialities 4(1): 82-86.

9. Khandelwal SA, Hada YS (2011) Eagles syndrome-A case report and review of the literature. Saudi Dent J 23(4): 211-215.

10. Uludağ İF, Öcek L, Zorlu Y, Uludağ B (2013) Eagle syndrome: case report. Agri 25(2): 87-89.

\section{Your next submission with Juniper Publishers will reach you the below assets}

- Quality Editorial service

- Swift Peer Review

- Reprints availability

- E-prints Service

- Manuscript Podcast for convenient understanding

- Global attainment for your research

- Manuscript accessibility in different formats

( Pdf, E-pub, Full Text, Audio)

- Unceasing customer service

Track the below URL for one-step submission https://juniperpublishers.com/online-submission.php 